\title{
Mutation screening of MSH2 and MLH1 mRNA in hereditary non-polyposis colon cancer syndrome
}

Nicola J Froggatt, Cecilia Brassett, D Jane Koch, D Gareth R Evans, Shirley V Hodgson, Bruce A J Ponder, Eamonn R Maher

\begin{abstract}
Germline mutations in four human mismatch repair genes (MSH2, MLH1, PMS1, and PMS2) have been reported to cause hereditary non-polyposis colon cancer syndrome (HNPCC). The identification of germline mutations in HNPCC kindreds allows precise diagnosis and accurate predictive testing. To investigate further the genetic epidemiology of HNPCC and the nature and frequency of germline mutations in this disorder, we studied 17 English HNPCC kindreds for germline mutations in MSH2 and MLH1. A previous genetic linkage study had suggested that most English HNPCC families will have mutations in one of these genes. Mutation analysis was performed in a three step process. (1) mRNA extracted from lymphoblastoid cell lines was analysed for gross rearrangements, (2) the in vitro transcription-translation (IVTT) assay was then performed to detect protein truncating mutations, and (3) partial cDNA sequencing of MSH2 or MLH1 was undertaken in families $(n=6)$ linked to MSH2 or MLH1 but without a detectable mutation. Seven different germline mutations were identified in eight of $17(47 \%)$ kindreds (five in MSH2 and three in MLH1). In three cases there was a deletion of a single exon in MSH2 mRNA, three mutations resulted in a truncated protein product, and two missense mutations were identified by direct sequencing. Six mutations were novel. No precise correlation between genotype and phenotype was observed, although a MSH2 missense (Thr905Arg) mutation was associated with a susceptibility to multiple colorectal polyps. Age related risks for colorectal and uterine cancer were similar for MSH2 and MLH1 mutations.

(F Med Genet 1996;33:726-730)
\end{abstract}

Key words: hereditary non-polyposis colorectal cancer; MSH2; MLH1.

Hereditary non-polyposis colon cancer syndrome (HNPCC) may account for up to $5 \%$ of all colorectal cancers, and is characterised by a dominantly inherited predisposition to early onset (mean 46 years) and multicentric colorectal cancer. ${ }^{1-3}$ In some families there is also an increased risk of extracolonic cancers, prin- cipally uterine, ovarian, and urothelial, and HNPCC can be subclassified into Lynch 1 and Lynch 2 in which extracolonic cancers are absent or present respectively. In addition, the Muir-Torre syndrome, which is characterised by the association of sebaceous cyst tumours and internal malignancy, is a further HNPCC variant. ${ }^{4}$ Germline mutations in four human mismatch repair genes, MSH2, MLH1, PMS1, and PMS2, may cause HNPCC, ${ }^{5-9}$ but there is relatively little information on the genetic epidemiology of HNPCC in different populations. In a previous genetic linkage study of 14 English HNPCC families we found evidence that mutations in $\mathrm{MSH} 2$ and $\mathrm{MLH} 1$ were likely to account for the majority of families studied. ${ }^{10}$ Although presymptomatic molecular genetic diagnosis improves the management of familial colorectal cancer, most HNPCC families are not suitable for linkage based predictive testing. We therefore investigated the frequency, nature, and phenotypic manifestation of MSH2 and MLH1 mutations in 17 English HNPCC families.

\section{Materials and methods}

PATIENTS

Lymphoblastoid cell lines were obtained from 17 probands from HNPCC families ascertained from East Anglia and north west England which met the standard criteria of the ICG for the diagnosis of HNPCC (at least three relatives with colorectal cancer in two or more generations, with at least one first degree relationship and with at least one patient diagnosed age $<50$ years). ${ }^{11}$ Non-colonic cancers known to be associated with the Lynch 2 phenotype (uterus, ovary, and ureter) occurred in eight families and a diagnosis of Muir-Torre syndrome was made in one kindred (C004). Tumour material was available from an affected member of nine kindreds and these tumours were investigated for microsatellite instability (RER phenotype).

MICROSATELLITE INSTABILITY DNA ANALYSIS Evidence of microsatellite instability was sought in tumours from affected members of nine families using five microsatellite polymorphisms: D3S1007, D3S1076, D5S346, D17S588, and CA5 on chromosome 2p, as described previously. ${ }^{10}$ The finding of microsatellite instability at two or more loci was considered significant. ${ }^{10}$ 
Table 1 Details of phenotype, number of people with colorectal cancer, linkage to MSH2 and MLH1 (from reference 10), and mutations identified (nucleotide and codons numbered as in references 5 and 6)

\begin{tabular}{|c|c|c|c|c|c|c|c|c|}
\hline \multirow[b]{2}{*}{ Family } & \multirow[b]{2}{*}{ Phenotype } & \multirow{2}{*}{$\begin{array}{l}\text { No of relatives } \\
\text { with colorectal } \\
\text { cancer }\end{array}$} & \multirow{2}{*}{$\begin{array}{l}\text { RER } \\
\text { status }\end{array}$} & \multicolumn{2}{|c|}{ Lod scores } & \multicolumn{3}{|c|}{ Mutation details } \\
\hline & & & & MSH2 & $M L H 1$ & Gene & $D N A / R N A$ abnormality & Effect on protein \\
\hline $\mathrm{C} 001$ & Lynch 2 & 3 & ND & 1.3 & -2.23 & & & \\
\hline $\mathrm{COO2}$ & Lynch 2 & 3 & ND & 1.16 & -3.53 & & & \\
\hline $\mathrm{C} 004$ & Muir-Torre & 5 & + & 1.52 & -5.56 & & & \\
\hline $\mathrm{C} 003$ & Lynch 1 & 7 & ND & 1.11 & -2.98 & MSH2 & $2782 \mathrm{C} \rightarrow \mathrm{G}$ Thr905Arg & Missense \\
\hline $\mathrm{C} 016$ & Lynch 2 & 4 & + & 1.54 & -3.46 & & & \\
\hline $\mathrm{C} 015$ & Lynch 2 & 6 & ND & 1.01 & -2.88 & & & \\
\hline $\mathrm{C} 006$ & Lynch 1 & 3 & + & 0.01 & 0.17 & & & \\
\hline $\mathrm{C} 008$ & Lynch 1 & 3 & + & -0.37 & 0.30 & MLH1 & 2163G $\rightarrow$ A Trp714Stop & Truncated \\
\hline $\mathrm{C} 022$ & Lynch 1 & 3 & ND & ND & ND & MSH2 & Exon 5 deleted owing to $3^{\prime}$ splice site mutation Ggta $a a \rightarrow G g t$ t $a a$ & Truncated \\
\hline $\mathrm{C} 007$ & Lynch 2 & 4 & + & -0.18 & -0.7 & MSH2 & Deletion exon 3 in RNA, no genomic DNA abnormality & Truncated \\
\hline $\mathrm{C} 010$ & Lynch 1 & 5 & + & -0.87 & 0.27 & MLH1 & $2062 \mathrm{G} \rightarrow \mathrm{A}$ Ala681 Thr & Missense \\
\hline $\mathrm{C} 017$ & Lynch 2 & 5 & + & & & MSH2 & Exon 5 deleted owing to 3 ' splice site mutation Ggta $a a \rightarrow G g t t a a$ & Truncated \\
\hline $\mathrm{C} 018$ & Lynch 1 & 3 & ND & ND & ND & & & \\
\hline $\mathrm{C} 019$ & Lynch 1 & 4 & ND & ND & ND & & & \\
\hline $\mathrm{C} 020$ & Lynch 1 & 6 & + & ND & ND & & & \\
\hline $\mathrm{C} 021$ & Lynch 2 & 3 & ND & ND & ND & MSH2 & $1257 \mathrm{C} \rightarrow \mathrm{T}$ Gln397Stop & Truncated \\
\hline
\end{tabular}

ND = not done.

\section{RNA ANALYSIS}

Total RNA was extracted from lymphoblastoid cell lines using TriZol reagent (Life Technologies) according to the manufacturer's instructions. First strand cDNA synthesis was performed using $1 \mu \mathrm{g}$ RNA and oligo-dT (Promega) with AMV reverse transcriptase (Promega) as directed. Initially $\mathrm{MSH} 2$ was amplified in four overlapping fragments as previously described, ${ }^{6}$ and these were analysed by agarose gel electrophoresis for detection of gross rearrangements.

In vitro transcription/translation was performed essentially as described by Liu et $a l^{12}$ using their primer sequences for $\mathrm{MSH} 2$, and those of Papadopoulos et at for MLH1. In brief, purified (Wizard purification kit, Promega) RT-PCR DNA was mixed with T7 RNA polymerase and $1 \mu \mathrm{Ci}{ }^{35} \mathrm{~S}$-L-methionine (translation grade, $1000 \mathrm{Ci} / \mathrm{mmol}$ at $10 \mathrm{mCi}$ / mol; Amersham Life Sciences) in a rabbit reticulocyte lysate based transcription/ translation system (TNT, Promega) and incubated at $30^{\circ} \mathrm{C}$ for two hours. Protein electro-

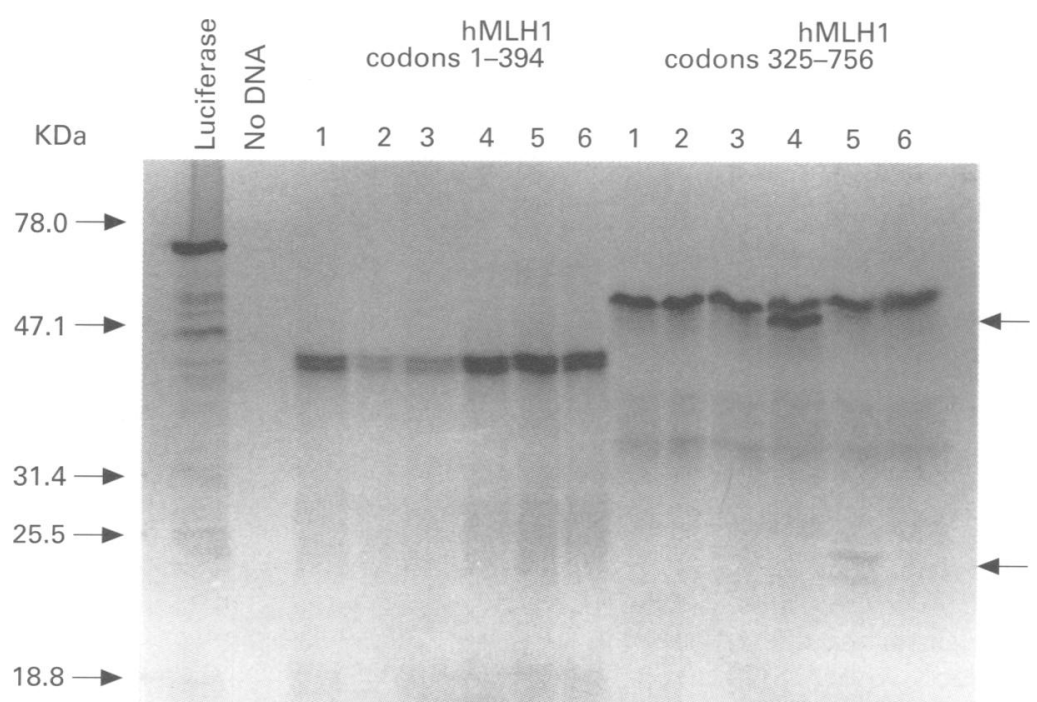

Figure 1 SDS-PAGE of in vitro transcription-translation products from $M L H 1$, showing truncated proteins in fragment 2 (codons 325-756) in tracks 4 (C008; Trp714Stop) and 5 (C009; 1472delA). phoresis was performed in $4 \%$ stacking/ $12 \%$ separating SDS-polyacrylamide gels, the gels fixed, dried under vacuum at $80^{\circ} \mathrm{C}$, and then exposed to BIOMAX film (Kodak) for one to seven days.

Any samples with detectable truncated proteins were investigated further by direct cDNA sequencing, both semiautomatic (PRISM Ready reaction dye deoxy terminator cycle sequencing kit, Applied Biosystems) and manual (fmol sequencing system, Promega). Base changes identified in this way were confirmed or denied by either further sequencing or restriction digestion, where possible, of the relevant exon from genomic PCR DNA.

The incidence of the two missense mutations detected (C003; MSH2 Thr905Arg, C010; MLH1 Ala681Thr) in the general population was investigated by restriction digestion. MLH1 Ala681Thr destroys a HinP1I site. Primers MLH1 18F (5' CGT ACC TAT TTT GAG GTA TTG AA 3') and 18R (5' AAG ATT GTA TAG GCC TGT CCT AG 3') were used to amplify a $201 \mathrm{bp}$ product. This was subsequently digested with HinP1I (New England Biolabs), generating $113 \mathrm{bp}$ and $88 \mathrm{bp}$ products in unaffected subjects, but remaining undigested in subjects carrying the alteration.

For detection of MSH2 Thr905Arg, a specific primer was designed such that the presence of the sequence alteration generates a HinfI site. Primers MSH2 16F (5' TTT AAT TAC TAA TGG GAC ATT CAC A 3') and x16T905R rev (5' CAG CTT TTA GCT GTT TTA ACT TGA T 3') generate a 141 bp product. After digestion with HinfI (New England Biolabs), products of $115 \mathrm{bp}$ and $26 \mathrm{bp}$ are seen in subjects carrying the alteration.

\section{Results}

Details of the clinical features and previous genetic linkage results ${ }^{10}$ for the 17 families are given in table 1 .

ANALYSIS OF MSH2 AND MLH 1 MRNA

Large deletions of MSH2 mRNA were detected in three kindreds (C017, C022, C007). Sequencing of the mutant mRNA and genomic 
DNA showed an identical deletion of exon 5 secondary to a $3^{\prime}$ splice site mutation in two kindreds (table 1). In $\mathrm{C} 007$ a deletion of exon 3 was detected in the MSH2 mRNA, but no abnormality was identified in genomic DNA.

\section{PROTEIN TRUNCATION ANALYSIS}

MSH2 and MLH1 cDNA was analysed for the presence of protein truncating mutations in the 14 kindreds without visible mRNA abnormalities. In vitro transcription-translation (IVTT) assay showed abnormalities in MLH1 in two kindreds: a single base frameshift deletion within exon 13 in $\mathrm{C} 009$ and a nonsense mutation in exon 19 in C008 (fig 1), and an alteration in $\mathrm{MSH} 2$ in one kindred, a nonsense mutation in exon 7 in $\mathrm{C} 021$ (table 1).

DETECTION OF MSH2 AND MLH1 MUTATIONS BY DIRECT SEQUENCING

To investigate if any of the 11 kindreds without an apparent mutation on mRNA and IVTT assay might have missense mutations, we partially sequenced MSH 2 or MLH1 cDNA in six kindreds where linkage had previously been suggested (MSH2: C001, C002, C003, C004, C016, and MLH1: C010). Abnormalities were defined in two kindreds. In $\mathrm{C003}$ there was a $\mathrm{Thr} \rightarrow$ Arg substitution at codon 905 in exon 16 of MSH2 (fig 2). The sequence change tracked with disease status and haplotype and was identified in all five affected subjects, but was not detected in 56 normal controls (data not shown). In $\mathrm{C} 010$ an $\mathrm{Ala} \rightarrow \mathrm{Thr}$ substitution was identified at codon 681 in exon 18 of MLH1 (table 1). The sequence change also tracked with the disease and haplotype and was present in all five affected relatives but not in 53 normal controls (data not shown). No mutation was identified in four kindreds (C001, C002, C004, C016) showing linkage to chromosome $2 \mathrm{p} 16$ markers despite sequencing $>60 \%$ of the MSH 2 coding sequence in each case.

GENOTYPE-PHENOTYPE CORRELATIONS

There were no significant differences between the incidence of Lynch 1 and Lynch 2 phenotypes according to whether MSH2 or MLH1 was mutated. Thus, of five families with MSH2 mutations, two had a Lynch 1 phenotype and three a Lynch 2 phenotype. Of three kindreds with MLH1 mutations, two had Lynch 1 and one a Lynch 2 phenotype. However, C003 kindred was notable because the phenotype overlapped with an attenuated polyposis phenotype and two of six relatives with the Thr905Arg substitution in MSH2 had $\sim 100$ adenomatous polyps. Age related risks for HNPCC related cancers were calculated for 50 subjects with MSH2 and MLH1 mutations. The age related risks for cancer for gene carriers were $15 \%$, $69 \%$, and $89 \%$ at 40,50 , and 60 years respectively. The predicted cancer risks at the age of 50 years were similar in subjects with $\mathrm{MSH} 2$ mutations $(n=27)$ and MLH1 mutations $(n=23)$ for (1) all cancers $(66 \%$ and $71 \%$ respectively), (2) colorectal cancer $(62 \% v$ $67 \%$ ), and (3) Lynch 2 extracolonic cancers (uterus, ovary, and ureter) (26\% and $29 \%$ ).
REPLICATION ERRORS IN COLORECTAL CANCERS Replication errors were detected at two or more of five loci analysed in colorectal cancers from all of the nine families available for analysis (table 1 ).

\section{Discussion}

Germline MSH2 and MLH1 mutations were identified in eight of 17 (47\%) HNPCC families investigated. In a previous study, seven of the 17 families had shown probable linkage to MSH2 $(n=6)$ or MLH1 $(n=1) \cdot{ }^{10}$ Germline mutations were detected here in one of six families with apparent linkage to MSH2 (lod score $>1$ ) and in the single family linked to MLH1. In addition, a germline mutation was detected in four families which were uninformative for linkage analysis. Six of the seven distinct mutations we detected were novel. The MSH 2 exon 5 splice site mutation identified in two families was also detected by Liu et $a l^{12}$ in three of 29 HNPCC families analysed. However, haplotyping of $\mathrm{C} 017$ and $\mathrm{C} 022$ has not shown evidence of a common haplotype (unpublished observations). We detected deletions of MSH 2 mRNA in three of 17 kindreds (17\%) compared to seven of 29 (24\%) studied

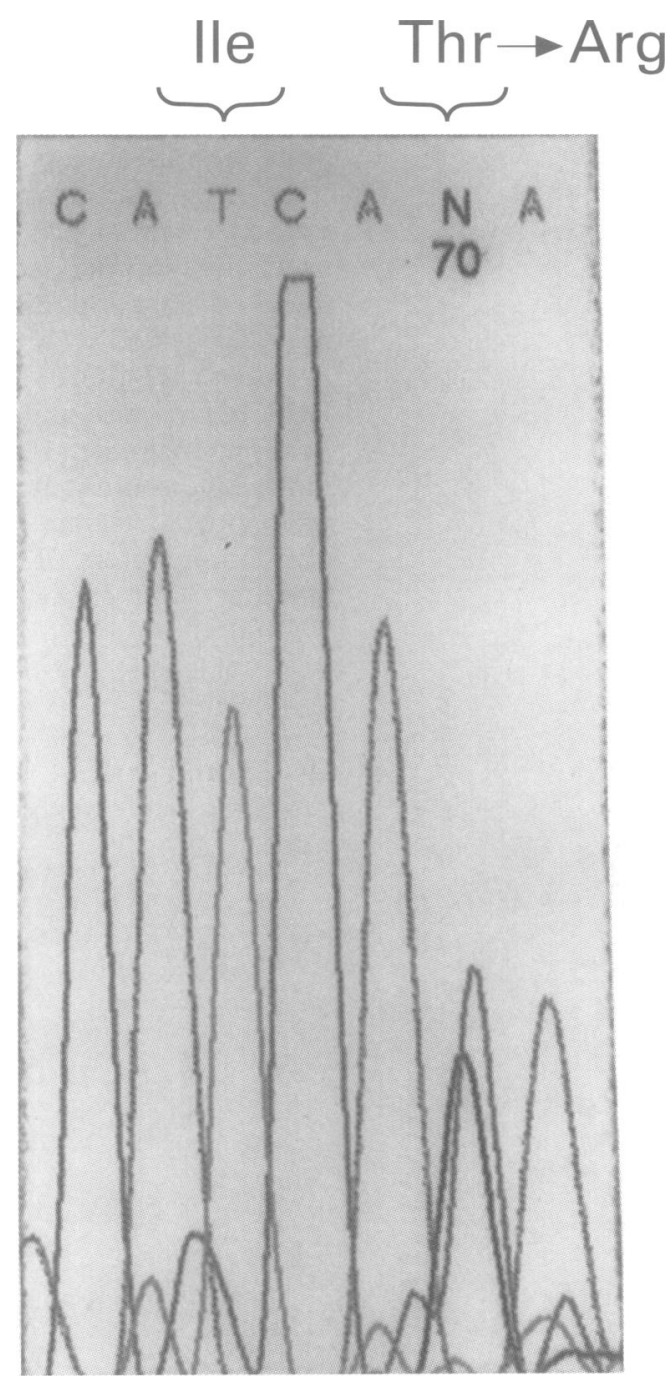

Figure 2 Semiautomatic sequencing electrophoretogram of codons 904-905 of MSH2 from C003, showing heterozygosity at the second position of codon 905 ( $A C A \rightarrow A G A ;$ Thr905Arg). 
by Liu et $a l^{12}$ using similar methods. In both studies, there are examples of patients with mRNA deletions in which a genomic sequence abnormality could not be identified. Many previously reported mutations in $\mathrm{MSH} 2$ and MLH1 are predicted to result in a truncated protein product, ${ }^{6812-15}$ but this may reflect the popularity of the in vitro transcriptiontranslation assay for mutation detection in HNPCC. Direct sequencing identified apparent missense mutations in two of our families ( $25 \%$ of identified mutations). These sequence variants are likely to be pathogenic as both (1) lead to substitutions of conserved amino acids, (2) track with the disease phenotype (colorectal cancer or multiple polyps or both), and (3) were not detected in normal controls. Although HNPCC is clinically heterogeneous with Lynch 1, Lynch 2, and Muir-Torre subtypes often distinguished, in practice these divisions may not be clear cut, ${ }^{16}$ and there are no clear genotype-phenotype correlations. Thus mutations in MSH2 and MLH1 can cause Lynch 1, Lynch 2, and Muir-Torre phenotypes. ${ }^{12}$ The age related cancer risks we calculated were based on data for all known gene carriers in a family. As all the families we analysed were selected because they satisfied the Amsterdam criteria, these risks may not be accurate for MSH2 or MLH1 mutations in non-Amsterdam criteria families. Most HNPCC patients have few polyps, but sometimes the distinction between HNPCC and attenuated familial polyposis coli can be equivocal. Mutations in the $5^{\prime}$ exons of the APC gene may cause an attenuated FAP phenotype. ${ }^{17}$ In our series, family $\mathrm{C} 003$ was notable because of the frequency of colorectal polyps in family members, including two who had $\sim 100$ polyps in colectomy specimens. However, this family is not linked to the APC gene and the Thr905Arg substitution in MSH2 is likely to be pathogenic. The identification of further families with this mutation will help resolve whether this mutation per se is associated with frequent polyps, or whether the observed phenotype in $\mathrm{COO} 3$ is a result of modifier genes. ${ }^{18}$

We found that although analysis of the MSH2 and MLH1 genes by inspection of transcript size and the protein truncation test can rapidly identify germline mutations, most HNPCC kindreds satisfying the ICG diagnostic criteria did not have an identifiable mutation using these methods (11 of 17). Other groups have also reported a lower than expected mutation detection rate. ${ }^{12} 19$ This may reflect inefficiency of the mutation detection techniques used or that, in contrast to the predictions from genetic linkage studies, $\mathrm{MSH} 2$ and MLH1 might not account for most HNPCC families. Our strategy would not detect mutations which resulted in an absent or unstable transcript. Buerstedde et $a l^{19}$ recently reported the highest mutation detection rate (6/10 Swiss HNPCC families) by sequencing each $\mathrm{MSH} 2$ and $\mathrm{MLH} 1$ exon and flanking sequence. However, even this labour intensive approach will not identify large germline deletions. Finally, we only analysed one person from each family and it is possible that some of these may by chance have been a phenocopy. In contrast to Finland, where most HNPCC families are accounted for by two ancestral mutations, ${ }^{820}$ there is no evidence for founder mutations in English HNPCC families. Thus, apart from the exon 5 splice mutation, none of our other six mutations were detected in a second family, and analysis of our families by a specific restriction site assay did not detect the MLH1 mutation (codon $519+1 \mathrm{~T}$ frameshift) reported by Kolodner et $a l^{13}$ in a very large family from north east England (data not shown). Although five families linked to chromosome 2 p16 did not have an identifiable MSH2 mutation, we cannot exclude the possibility that these families have a mutation in the mismatch repair enzyme gene (GTBP or p160), which also maps to this region. ${ }^{2122}$ Although Jass $e t a l^{3}$ have reported that only 12 of 19 HNPCC kindreds satisfying the ICG criteria had tumour microsatellite instability, all HNPCC families in our data set were RER positive. Further studies of RER status and MSH2 and MLH1 mutation analysis in different centres are required to resolve the genetic epidemiology of HNPCC fully.

We thank the Cancer Research Campaign (CRC) and Addenbrooke's NHS Trust Endowment Fund for financial support, Bo Liu and Lizette van Rensburg for helpful discussion, and the many colleagues who have provided us with access to families.

1 Vasen HF, Offerhaus GJ, den Hartog Jager FC, et al. The tumour spectrum in hereditary non-polyposis colorectal cancer: a study of 24 kindreds in the Netherlands. Int $\mathcal{f}$ Cancer 1990;46:31-4.

2 Lynch HT, Lanspa S, Smyrk T, Boman B, Watson P, Lynch $\mathrm{J}$. Hereditary nonpolyposis colorectal cancer (Lynch syndromes I \& II). Genetics, pathology, natural history, and cancer control. Part I. Cancer Genet Cytogene 1991;53:143-60.

3 Lynch HT, Lynch JF. The Lynch syndromes. Curr Opin Oncol 1993;5:687-96.

4 Hall NR, Williams AT, Murday VA, Newton JA, Bishop DT Muir-Torre syndrome: a variant of the cancer family synMuir-Torre syndrome: a variant of the
drome. 7 Med Genet 1994;31:627-31.

5 Fishel R, Lescoe MK, Rao MRS, et al. The mutator gene homolog MSH2 and its association with hereditary nonpolyposis colorectal cancer. Cell 1993;75:1027-38.

6 Leach FS, Nicolaides NC, Papadopoulos N, et al. Mutation of a mutS homolog in hereditary nonpolyposis colorectal cancer. Cell 1993;75:1215-25.

7 Bronner CE, Baker SM, Morrison PT, et al. Mutation in the DNA mismatch repair gene homologue hMLH1 is associated with hereditary non-polyposis colon cancer. Nature 1994;368:258-61.

8 Papadopoulos N, Nicolaides NC, Wei YF, et al. Mutation of a mutL homolog in hereditary colon cancer. Science 1994; 263:1625-9.

9 Nicolaides NC, Papadopoulos N, Liu B, et al. Mutations of two PMS homologues in hereditary non-polyposis colon two PMS homologues in heredir. Nature 1994;371:75-80.

10 Froggatt NJ, Koch J, Davies R, et al. Genetic linkage analysis in hereditary non-polyposis colon cancer syndrome. $f$ Med Genet 1995;32:352-7.

11 Vasen HF, Mecklin JP, Khan PM, Lynch HT. The International Collaborative Group on Hereditary NonPolyposis Colorectal Cancer (ICG-HNPCC). Dis Colon Rectum 1991;34:424-5.

12 Liu B, Parsons RE, Hamilton SR, et al. hMSH2 mutations in hereditary non-polyposis colorectal cancer kindreds. Cancer Res 1994;54: 4590-4.

13 Kolodner RD, Hall NR, Lipford J, et al. Structure of the human MLH1 locus and analysis of a large hereditary nonpolyposis colorectal carcinoma kindred for mlh mutations. Cancer Res 1995;55:242-8.

14 Wijnen J, Vasen $\mathrm{H}$, Khan PM, et al. Seven new mutations in hMSH2, an HNPCC gene, identified by denaturing
gradient-gel electrophoresis. Am $\mathcal{f}$ Hum Genet 1995; 56:1060-6.

15 Han HJ, Maruyama M, Baba S, Park JG, Nakamura Y. Genomic structure of human mismatch repair gene, hMLH1, and its mutation analysis in patients with heredi- 
tary non-polyposis colorectal cancer (HNPCC). Hum Mo Genet 1995;4:237-42.

16 Lynch HT, Fusaro RM, Roberts L, Voorhees GJ, Lynch JF. Muir-Torre syndrome in several members of a family with a variant of the cancer family syndrome. Br 7 Dermatol a variant of the cancis:

17 Spirio L, Olschwang S, Groden J, et al. Alleles of the APC gene: an attenuated form of familial polyposis. Cell 1993;75:951-7.

18 MacPhee M, Chepenik KP, Liddell RA, Nelson KK, Siracusa LD, Buchberg AM. The secretory phospholipase A2 gene is a candidate for the mom 1 locus, a major modifier of $A P C^{\text {min }}$-induced intestinal neoplasia. Cell 1995; 81:957-66.

19 Buerstedde JM, Alday P, Torhurst J, Weber W, Muller H, Scott R. Detection of new mutations in six out of 10 Swis
HNPCC families by genomic sequencing of the hMSH2 and hMLH1 genes. $\mathcal{F}$ Med Genet 1995;32:909-12.

20 Nystrom-Lahti M, Kristo P, Nicolaides NC, et al. Founding mutations and Alu-mediated recombination in hereditary colon cancer. Nature Med 1995;1:1203-6. 21 Drummond JT, Li GM, Longley MJ, Modrich P. Isolation
of an hMSH2-p160 heterodimer that restores DNA mismatch repair to tumour cells. Science 1995;268:190912.

22 Palombo F, Gallinari P, Iaccarino I, et al. GTBP, a 160-kilodalton protein essential for mismatch-binding activity in human cells. Science 1995;268:1912-17.

23 Jass JR, Cottier DS, Jeevaratnam P, et al. Diagnostic use of microsatellite instability in hereditary non-polyposis colorectal cancer. Lancet 1995;346:1200-1. 